\title{
Author Correction: Global consumption and international trade in deforestation-associated commodities could influence malaria risk
}

\author{
Leonardo Suveges Moreira Chaves (D), Jacob Fry (D), Arunima Malik, Arne Geschke (D), Maria Anice Mureb Sallum \\ \& Manfred Lenzen (1)
}

Correction to: Nature Communications https://doi.org/10.1038/s41467-020-14954-1, published online 09 March 2020.

The original version of the Article omitted details from the Methods section explaining the weighting scheme in the regression analysis. It was not clear in the original Methods text that the authors weighted some years more than others in the analysis.

To more thoroughly explain the methods, the new version of the Article has the following paragraph between the original first and second paragraphs of the "Multiple regression" section of the Methods:

“The malaria incidences for the years 2001, 2005 and 2014 were poorly represented by an unweighted regression model. To this end, we attempted to fit the incidence curve with a weighted function including interventions and tree cover loss (TCL). This approach is justified because the goal of our regression is to model the influence of deforestation on malaria incidence. Without weighting, a significant and positive regression coefficient for TCL cannot be obtained. The regression formula including weights $w(t)$ as is $w(t) \sum_{r} I_{r}(t)=\beta_{0}+\beta_{L} w(t) \sum_{r} L_{r}(t)+\beta_{n} w(t) n(t)+\beta_{a} w(t) a(t)$, with weights being 17.86 percent for $2001,42.86$ percent for 2005 and 16.07 percent for 2014. The regression coefficients from this approach are $\beta_{0}=164.1, \beta_{L}=0.43, \beta_{n}=-243.3$, and $\beta_{a}=-72.4$. The choice of weights has only a small influence on regression outcomes, and the land cover coefficient is similar to that found by MacDonald and Mordecai (2019), who found a value of 3.3\% increase in malaria incidence as a result of $10 \%$ increase in forest cover loss."

In the data file originally provided on Zenodo, there were duplicated rows for years 2001, 2005 and 2014 which were weighted more heavily, but these rows were hidden. For the sake of transparency, the dataset has also been updated with the rows unhidden; the data file can be accessed on Zenodo (https://doi.org/10.5281/zenodo.4536029). These errors have been corrected in the original PDF and HTML versions of the article.

Published online: 11 June 2021

Open Access This article is licensed under a Creative Commons Attribution 4.0 International License, which permits use, sharing, adaptation, distribution and reproduction in any medium or format, as long as you give appropriate credit to the original author(s) and the source, provide a link to the Creative Commons license, and indicate if changes were made. The images or other third party material in this article are included in the article's Creative Commons license, unless indicated otherwise in a credit line to the material. If material is not included in the article's Creative Commons license and your intended use is not permitted by statutory regulation or exceeds the permitted use, you will need to obtain permission directly from the copyright holder. To view a copy of this license, visit http://creativecommons.org/licenses/by/4.0/.

(C) The Author(s) 2021 